\title{
Database proton NMR chemical shifts for RNA signal assignment and validation
}

\author{
Shawn Barton • Xiao Heng $\cdot$ Bruce A. Johnson • \\ Michael F. Summers
}

Received: 23 August 2012 / Accepted: 2 November 2012/Published online: 23 November 2012

(C) The Author(s) 2012. This article is published with open access at Springerlink.com

\begin{abstract}
The Biological Magnetic Resonance Data Bank contains NMR chemical shift depositions for 132 RNAs and RNA-containing complexes. We have analyzed the ${ }^{1} \mathrm{H}$ NMR chemical shifts reported for non-exchangeable protons of residues that reside within A-form helical regions of these RNAs. The analysis focused on the central base pair within a stretch of three adjacent base pairs (BP triplets), and included both Watson-Crick (WC; G:C, A:U) and G:U wobble pairs. Chemical shift values were included for all $4^{3}$ possible WC$\mathrm{BP}$ triplets, as well as 137 additional triplets that contain one or more G:U wobbles. Sequence-dependent chemical shift correlations were identified, including correlations involving terminating base pairs within the triplets and canonical and non-canonical structures adjacent to the BP triplets (i.e. bulges, loops, WC and non-WC BPs), despite the fact that the NMR data were obtained under different conditions of $\mathrm{pH}$, buffer, ionic strength, and temperature. A computer program (RNAShifts) was developed that enables convenient
\end{abstract}

Electronic supplementary material The online version of this article (doi:10.1007/s10858-012-9683-9) contains supplementary material, which is available to authorized users.

\section{S. Barton $\cdot$ X. Heng $\cdot$ M. F. Summers}

Howard Hughes Medical Institute, University of Maryland,

Baltimore County, 1000 Hilltop Circle, Baltimore, MD 21250,

USA

S. Barton · X. Heng - B. A. Johnson - M. F. Summers ( $\square)$

Department of Chemistry and Biochemistry,

University of Maryland, Baltimore County, 1000 Hilltop Circle,

Baltimore, MD 21250, USA

e-mail: summers@hhmi.umbc.edu

B. A. Johnson $(\square)$

One Moon Scientific, Inc., 839 Grant Ave., Westfield, NJ 07090,

USA

e-mail: bruce@onemoonscientific.com comparison of RNA ${ }^{1} \mathrm{H}$ NMR assignments with database predictions, which should facilitate future signal assignment/ validation efforts and enable rapid identification of noncanonical RNA structures and RNA-ligand/protein interaction sites.

Keywords RNA - Chemical shift - A-form helices . NMR signal assignment and validation

$\begin{array}{ll}\text { Abbreviations } \\ \text { BMRB } & \text { Biological Magnetic Resonance Data Bank } \\ \text { NDB } & \text { Nucleic Acid Database } \\ \text { PDB } & \text { Protein Data Bank } \\ \text { WC-BP } & \text { Watson-Crick base pair } \\ \text { G/g } & \text { Guanosine } \\ \text { N/n } & \text { Any nucleotide } \\ \text { R/r } & \text { Purine } \\ \text { Py/py } & \text { Pyrimidine } \\ \text { A/a } & \text { Adenosine } \\ \text { C/c } & \text { Cytosine } \\ \text { U/u } & \text { Uridine } \\ \langle\delta\rangle & \text { Mean NMR chemical shift } \\ \langle\delta\rangle_{\text {can }} & \text { Mean NMR chemical shift determined for a } \\ & \text { canonical triplet, defined here as a stretch of } \\ & \text { three sequential canonical base pairs that is both } \\ & \text { preceded and followed by at least one canonical } \\ & \text { base pair } \\ \delta_{\text {pred }} & \text { Predicted NMR chemical shift }\end{array}$

\section{Introduction}

RNA molecules participate in a large and expanding array of known biological functions including gene regulation, maintenance of sub-cellular and viral structure, 
intracellular trafficking, antiviral restriction, catalysis, and, of course, propagation of genetic information (Korostelev and Noller 2007; Steitz 2008; Bessonov et al. 2008; Boisvert et al. 2007; Wakeman et al. 2007; Edwards et al. 2007; Bartel 2004; Kim 2005; Hassouna et al. 1984; Brodersen and Voinnet 2006; Doudna and Rath 2002; Ponting et al. 2009). Like proteins, the functional activities of most RNAs are intrinsically linked to their structures. Unfortunately, although a wealth of structural information is currently available for functionally active proteins and protein domains, structural information for functionally relevant RNAs remains relatively limited. Thus, the Protein Data Bank (PDB; http://www.rcsb.org/pdb/home/home.do) currently contains more than 55,000 protein structure depositions, whereas the Nucleic Acid Database (NDB; http://ndbserver.rutgers.edu/) contains atomic coordinate depositions for fewer than $\sim 2,100$ RNAs and protein/ ligand-RNA complexes, of which $\sim 1,600$ were determined by X-ray crystallography and $\sim 500$ by NMR spectroscopy. Conformational heterogeneity and the presence of a relatively uniform, negative surface charge can hinder structural studies by X-ray crystallography, and as discussed below, difficulties associated primarily with limited chemical shift dispersion have generally limited NMR applications to relatively small RNAs. For these reasons, much of what is known about the structures of biologically functional RNAs (primarily secondary structure information) has been obtained by chemical and enzymatic accessibility mapping experiments, coupled with phylogenetic and free energy calculations. Although RNA probing methodologies are potentially very powerful and have been widely applied (Peattie and Gilbert 1980; Ehresmann et al. 1987; Stern et al. 1988; Forconi and Herschlag 2009; Weeks 2010), interpretation of the data can be problematic, particularly for RNAs that exist as equilibrium mixtures of multiple conformational species (see for example, Kladwang et al. 2011; Houck-Loomis et al. 2011; Lu et al. 2011a,b; Miyazaki et al. 2010).

NMR is a potentially powerful tool for probing RNA structure (Wüthrich 1986; Allain and Varani 1997; Lukavsky and Puglisi 2005), but its application to larger RNAs can be complicated by a number of factors. Inter-residue scalar couplings are generally weak, limiting the utility of "through bond" inter-residue connectivity experiments for signal assignment. The most commonly used assignment approach involves identification of sequential inter-residue NOE connectivities (Wüthrich 1986), but even this approach can be problematic for modest sized RNAs (ca. 25-60 nucleotides). Although resolution can be increased by ${ }^{1} \mathrm{H}-{ }^{13} \mathrm{C}$ heteronuclear spectral editing (Peterson et al. 2004; D'Souza et al. 2004; D'Souza and Summers 2004; Davis et al. 2005; Batey et al. 1995; Batey et al. 1992; Nikonowicz and Pardi 1992; Nikonowicz et al. 1992; Michnicka et al. 1993; Kim et al.
1995; Xu et al. 1996; Kim et al. 2002; Lukavsky et al. 2003; Lu et al. 2009), chemical shift dispersion is relatively limited (Allain and Varani 1997; Lukavsky and Puglisi 2005), and severe dipolar broadening of the aromatic ${ }^{1} \mathrm{H}-{ }^{13} \mathrm{C}$ signals that are critical for structural analysis can preclude detection of ${ }^{1} \mathrm{H}-{ }^{13} \mathrm{C}$ correlation NMR signals in larger RNAs (Lu et al. 2011a). In addition, interproton distances between elements of secondary structure in larger RNAs typically exceed those required for NOE detection ( $\mathrm{Lu}$ et al. 2009; Tolbert et al. 2010). Thus, high-resolution NMR-based structural studies have been applied mainly to relatively small RNAs: Of the 496 RNA NMR structures that have been deposited in the NDB, only 19 contain 60 or more nucleotides; the largest is a symmetrical dimer of 132 nucleotides (two 66 nucleotide subunits), and the average size is $\sim 27$ nucleotides.

One approach for addressing issues of signal degeneracy involves the application of traditional 2D NOESY experiments to RNA samples that are site- and/or nucleotide-specifically labeled with deuterium (Miyazaki et al. 2010; D'Souza et al. 2004; Davis et al. 2005; Kim et al. 1995; Lu et al. 2009; Zhou et al. 2006; Nelissen et al. 2008; Heng et al. 2012; Duss et al. 2012). ${ }^{2} \mathrm{H}$-isotope edited 2D NMR has enabled nearly complete assignment of the aromatic, $\mathrm{H}_{1}{ }^{\prime}$, $\mathrm{H}_{2}{ }^{\prime}$, and $\mathrm{H}_{3}{ }^{\prime}$ ribose signals of RNAs containing up to 132 nucleotides (Miyazaki et al. 2010), and has also enabled assignment of selected residues within a 720 nucleotide RNA (Lu et al. 2011a; Heng et al. 2012). This approach, which involves comparison of high resolution 2D NOESY spectra obtained for multiple, differentially ${ }^{2} \mathrm{H}$-labeled samples, avoids relaxation problems associated with aromatic ${ }^{1} \mathrm{H}-{ }^{13} \mathrm{C}$ spectral editing and enables observation of signals in $2 \mathrm{D}{ }^{1} \mathrm{H}-{ }^{1} \mathrm{H}$ NOESY spectra for protons with $\mathrm{T}_{2}$ values as short as $8 \mathrm{~ms}$ (Lu et al. 2011a). Although resolution and sensitivity can be improved dramatically by nucleotidespecific deuteration, signal overlap can still hinder the assignment process for RNAs comprising more than 150 nucleotides (Summers and coworkers, unpublished).

NMR chemical shifts have been widely utilized for NMR signal assignment and structural studies of proteins (for examples see: Grzesiek and Bax 1993; Wishart and Sykes 1994; Wishart et al. 1991, 1992; Cavalli et al. 2007; Shen et al. 2008; Wishart et al. 2008). Although relationships between ${ }^{13} \mathrm{C}$ chemical shifts and RNA structure have been identified (Ebrahimi et al. 2001; Fares et al. 2007; Ohlenschlager et al. 2008), and ${ }^{15} \mathrm{~N}$ NMR chemical shifts have been incorporated into a probabilistic approach for automated assignment of RNA imino groups (Bahrami et al. 2012), heteronuclear NMR chemical shifts have not been widely exploited for RNA studies (Lam and Chi 2010; Aeschbacher et al. 2012). On the other hand, Wijmenga and co-workers showed that non-exchangeable ${ }^{1}$ H NMR chemical shifts for A-form helical residues could be back-calculated from a given 3D RNA structure 


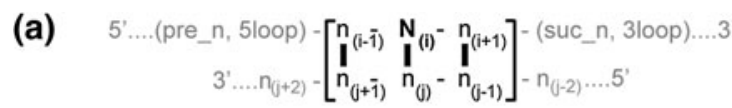

(b)

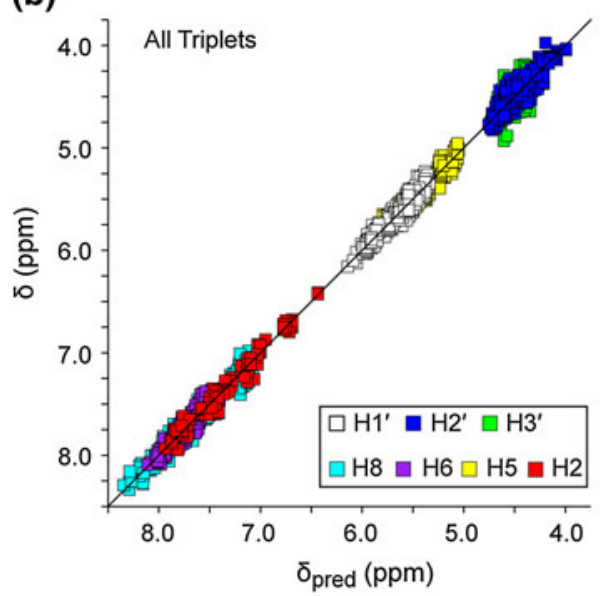

Fig. 1 a Definitions used for base pair triplets. The chemical shifts of the $\mathrm{N}_{(\mathrm{i})}$ residue are analyzed in this work, and this strand may be preceded by a base-paired (WC or GU wobble) nucleotide (pre_n) or a non-base paired residue (5loop), or followed by a base-paired residue (suc_n) or non-base paired residue (3loop). b Plot of the database chemical shift (automatically re-referenced as described in

(Cromsigt et al. 2001). For 28 examples tested, the backcalculated shifts were in good agreement with shifts reported in the Biological Magnetic Resonance Bank (BMRB; www.bmrb.wisc.edu), and some general ${ }^{1} \mathrm{H}$ NMR chemical shift trends were identified (Cromsigt et al. 2001). Here we report a detailed analysis of the $\mathrm{H}_{8}, \mathrm{H}_{2}, \mathrm{H}_{6}, \mathrm{H}_{5}$, $\mathrm{H}_{1}{ }^{\prime}, \mathrm{H}_{2}{ }^{\prime}$, and $\mathrm{H}_{3}{ }^{\prime}$ proton NMR chemical shifts that have been deposited in the BMRB. After correcting for differences in chemical shift referencing and sample conditions, excellent correlations were observed, despite the fact that the data were obtained over a wide range of sample conditions. Our findings confirm and quantify previously identified trends and identify new sequence- and structuredependent chemical shift correlations that can be used for assignment and/or validation of non-exchangeable ${ }^{1} \mathrm{H}$ NMR chemical shifts and for the identification of noncanonical RNA structural features and intermolecular interaction sites.

\section{Methods}

NMR data were analyzed using "RNAShifts", a program designed to download and analyze RNA ${ }^{1} \mathrm{H}$ NMR chemical shifts that have been deposited in the BMRB. (Locally derived shifts that have yet to be deposited can also be analyzed). All 131 depositions available in the BMRB were used in the current analysis except BMRB ID 5170, 6814, 4816, $15697,15915,5023,4253,4894$, and 15257 , which could not (c)

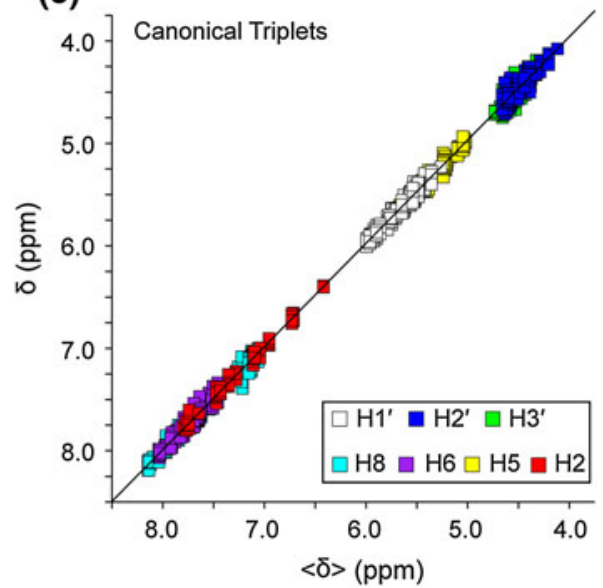

the text) $(\delta)$ versus calculated chemical shift $\left(\delta_{\text {pred }}\right)$ for the 3758 assignment depositions utilized in the present study (rms deviation $=0.056)$. c Plot of $\delta$ versus mean chemical shift $(\langle\delta\rangle)$ for residues in canonical triplets (triplets that contain only GC and/or AU base pairs and are both preceded and followed by a GC and/or AU base pair) $(\mathrm{rms}$ deviation $=0.043)$

be reliably used because either the BMRB assignments didn't match the published PDB assignments, or because there was no associated publication or PDB file that could be used to identify RNA secondary structure. As additional input, files were manually generated for each deposition, based on published structural studies, that identify for each residue (1) whether or not the residue is base-paired, (2) the nature of the base-pairing partner, (3) any long-range intraand/or inter-molecular interactions (e.g., sites of protein binding or participation in A-minor or other RNA-RNA contacts), (4) participation in structured (e.g., GNRA; $\mathrm{G} / \mathrm{g}=$ guanosine, $\mathrm{N} / \mathrm{n}=$ any nucleotide; $\mathrm{R} / \mathrm{r}=$ purine; $\mathrm{A} / \mathrm{a}=$ adenosine) or unstructured loops. A representative input file is shown in Supplementary Table S1.

The analysis focused on shifts reported for the nonexchangeable $\mathrm{H}_{8}, \mathrm{H}_{2}, \mathrm{H}_{6}, \mathrm{H}_{5}, \mathrm{H}_{1}{ }^{\prime}, \mathrm{H}_{2}{ }^{\prime}$ and $\mathrm{H}_{3}{ }^{\prime}$ protons of the central base pair of three consecutive canonical WatsonCrick base-pairs (WC-BPs) (here called WC-BP triplets: $\left(\left[5^{\prime}-\mathrm{n}_{(\mathrm{i}-1)}-\mathrm{N}_{\mathrm{i}}-\mathrm{n}_{(\mathrm{i}+1)}\right]:\left[5^{\prime}-\mathrm{n}_{(\mathrm{j}-1)}-\mathrm{n}_{\mathrm{j}}-\mathrm{n}_{(\mathrm{j}+1)}\right] ; \mathrm{N}_{\mathrm{i}}=\right.$ nucleotide for which the NMR shifts are being evaluated; $\mathrm{n}=$ neighboring nucleotides), Fig. 1a. As additional parameters, we denoted if the $\mathrm{n}_{(\mathrm{i}-1)}: \mathrm{n}_{(\mathrm{j}+1)}$ or $\mathrm{n}_{(\mathrm{i}+1)}: \mathrm{n}_{(\mathrm{j}-1)}$ base pairs were at terminating positions in the RNA, and we identified the secondary structural elements adjacent to the WC-BP triplets (canonical or non-canonical WC-BP, bulges, loops, long-range RNA-RNA interactions, and RNAprotein/ligand interactions), Table S1.

We chose a relatively conservative approach in modeling the effect of the neighborhood of each central base pair. This 
was done because there are still, especially in comparison to proteins, relatively few chemical shift assignment sets for RNA deposited at the BMRB. Rather than using any nonlinear or neural network approach we used an approach similar to the chemical shift increment method of Pretsch as used in predicting spectra of small organic molecules (Pretsch et al. 2009). Thus, for the central residue of each WC-BP triplet, we defined the attributes describing the neighborhood of the central nucleotide as described above, and calculated the contribution that each attribute makes to the predicted chemical shift. The predicted chemical shift is then a base chemical shift plus the linear contribution of the value corresponding to each attribute present in that nucleotide's environment. The contribution of each attribute was calculated by linear regression of the chemical shifts in our database of RNA chemical shifts with the set of explanatory variables represented by the neighborhood attributes. The constant term of our regression model corresponds to a nucleotide embedded in a triplet of Watson-Crick base pairs with a $U$ (uridine) flanking it on both the $5^{\prime}$ and $3^{\prime}$ sides and Watson-Crick basepaired nucleotides at the $5^{\prime}$ and $3^{\prime}$ ends of the triplet.

Our analysis included a total of 15 potential variables, Table 1 , of which only some might potentially contribute significantly to the shift of a specific atom in a given central nucleotide. Because the approach includes a large number of independent variables relative to the chemical shift datasets, there was a significant danger of over-fitting using a conventional linear regression algorithm. Over-fitting can lead to excellent prediction of the training set, but poor predictive capability on novel datasets. To minimize the risk of overfitting we chose an algorithm, Pace Regression (Projection Adjustment by Contribution Estimation), that is capable of assessing the importance of each of the parameters. Calculations were performed using the Weka Machine Learning and Data Mining Library system, which allowed us to perform a statistical analysis of the prediction model (Witten et al. 2011). Pace Regression is a linear regression system that uses various information criteria to assess the degree of importance of the regression variables (Wang and Witten 2002). Thus it provides one solution to the subset selection problem: which subset of a set of potential regressors is the appropriate set to explain the data, and thereby minimize the risk of overfitting and maximize the predictive capability on previously unseen data.

Use of Weka provided not only access to Pace Regression, but also various assessments of the quality of the predictions. In particular, we used 10-fold stratified crossvalidation during our analysis. Rather than providing correlation coefficients and root mean squared (rms) deviations of the predictions using all the data in the prediction, this technique trains the model on $90 \%$ of the data and then assesses the results of predicting the remaining $10 \%$ of the data. The process is repeated 10 times, using a different subset of the data each time and derives the correlation coefficients and rms deviations based on the whole process. Pace regression was used independently on each atom type present in each of the four central nucleotides for a total of 19 regression calculations.

We were unable in our analysis to adequately identify and control for sample conditions $(\mathrm{pH}$, temperature, ionic strength, etc.) and unusual molecular conformation, and there is a significant possibility of misassignment, especially of some atom types. Therefore, after dropping a single obvious major outlier, we minimized these effects by automatically trimming outliers and automatically adjusting the reference for the chemical shift sets. Automated outlier elimination was performed by running two passes of the Pace Regression for each atom/central nucleotide. In the first pass, the rms deviations between the experimental and predicted values were calculated using all of the data. Any data values that deviated from the predicted values by more than three times the rms deviation value were dropped, and a second pass of the Pace Regression was performed on the now trimmed dataset. Automatic re-referencing was achieved by performing the above analysis (including outlier detection) twice. In the first of these passes, the mean error of prediction was calculated for all the shifts from each BMRB file. Prior to the second pass, each shift was corrected by the mean deviation calculated for the corresponding BMRB file. The chemical shift corrections determined by this approach are listed in Table S3.

The RNAShifts program was written using JTcl (http://jtcl.kenai.com) and Swank (http://swank.kenai.com ), which are the Java implementations of the Tcl programming language and Tk graphical user interface toolkit (Ousterhout and Jones 2010). The analysis mode is run in three stages. The first loads BMRB files (fetching them from http://bmrb.wisc.edu if necessary), extracts chemical shifts, and then uses the input template to assign attributes to each shift. The second stage reads the output of the first stage and generates input files in the format used by Weka. The third executes Weka multiple times for each proton type, manages the two passes used for outlier detection and generates various statistical output files. The graphical interface module allows plotting predicted and experimental data subject to various criteria for choosing subsets of the data and attributes for plotting. The RNAShifts program is available upon request from the author (BAJ).

\section{Results and discussion}

Outlier chemical shifts

The statistical analysis described above identified 65 chemical shift assignments from the full BMRB database 
Table 1 Sequence variables and chemical shift corrections calculated by Pace regression

\begin{tabular}{|c|c|c|c|c|c|c|c|c|c|c|c|c|}
\hline Atom & const & pre_a & pre_c & pre_g & \multicolumn{2}{|c|}{ pre_gu } & pre_ug & suc_a & suc_c & \multicolumn{2}{|c|}{ suc_g } & suc_gu \\
\hline \multicolumn{13}{|l|}{ Part 1} \\
\hline $\mathrm{A}-\mathrm{H}_{2}$ & 7.0299 & 0.6672 & 0.2521 & 0.6899 & \multicolumn{2}{|c|}{0.7637} & 0.2555 & -0.5934 & 0.0658 & \multicolumn{2}{|r|}{0.2814} & -0.3321 \\
\hline $\mathrm{A}-\mathrm{H}_{8}$ & 8.1525 & -0.4169 & -0.1145 & -0.3709 & \multicolumn{2}{|c|}{-0.3808} & 0.2107 & -0.1006 & 0.0379 & \multicolumn{2}{|r|}{-0.0723} & 0.0458 \\
\hline $\mathrm{G}-\mathrm{H}_{8}$ & 7.7036 & -0.5622 & -0.1595 & -0.497 & \multicolumn{2}{|c|}{-0.5083} & 0.2215 & -0.0383 & 0.0562 & \multicolumn{2}{|c|}{-0.0265} & 0.0369 \\
\hline $\mathrm{C}-\mathrm{H}_{5}$ & 5.6724 & -0.4611 & -0.1625 & -0.4304 & \multicolumn{2}{|c|}{-0.2815} & 0.0377 & -0.0222 & -0.0368 & & -0.0249 & -0.032 \\
\hline $\mathrm{U}-\mathrm{H}_{5}$ & 5.5639 & -0.5133 & -0.1778 & -0.5018 & -0.3 & & -0.0469 & 0.0333 & 0.0165 & & 0 & 0.0348 \\
\hline $\mathrm{C}-\mathrm{H}_{6}$ & 7.8627 & -0.3901 & -0.0867 & -0.2215 & -0.2 & & 0.085 & -0.0253 & 0.0363 & & -0.0288 & -0.0833 \\
\hline $\mathrm{U}-\mathrm{H}_{6}$ & 7.9946 & -0.3643 & -0.1083 & -0.2523 & -0.3 & & 0.0832 & -0.0402 & 0.0332 & & -0.0555 & -0.0809 \\
\hline $\mathrm{A}-\mathrm{H}_{1}{ }^{\prime}$ & 5.9905 & -0.1042 & -0.05 & 0 & -0. & & 0 & -0.0823 & 0 & & -0.0324 & 0.0528 \\
\hline $\mathrm{G}-\mathrm{H}_{1}{ }^{\prime}$ & 5.7539 & -0.1822 & -0.0584 & -0.019 & -0. & & -0.0373 & 0 & 0.0216 & & 0.0198 & 0.0777 \\
\hline $\mathrm{C}-\mathrm{H}_{1}{ }^{\prime}$ & 5.56 & -0.1805 & -0.0825 & -0.0446 & -0. & & 0.039 & -0.0226 & -0.0139 & & 0.0134 & 0.0711 \\
\hline $\mathrm{U}-\mathrm{H}_{1}{ }^{\prime}$ & 5.6203 & -0.1679 & -0.0865 & -0.1049 & -0 & & 0.0234 & -0.0405 & 0.0097 & & 0.0196 & 0.0571 \\
\hline $\mathrm{A}-\mathrm{H}_{2}{ }^{\prime}$ & 4.4575 & -0.0269 & 0.0268 & 0.0309 & -0. & & 0.1174 & 0.1041 & 0.0496 & & 0.1613 & 0.1416 \\
\hline $\mathrm{G}-\mathrm{H}_{2}^{\prime}$ & 4.4582 & -0.0666 & 0.0389 & 0 & 0 & & 0.0794 & 0.1367 & 0.0248 & & 0.1286 & 0.0705 \\
\hline $\mathrm{C}-\mathrm{H}_{2}{ }^{\prime}$ & 4.3454 & -0.1298 & 0.0188 & 0.0499 & -0. & & 0.0363 & 0.1475 & 0 & & 0.1557 & 0.1724 \\
\hline $\mathrm{U}-\mathrm{H}_{2}{ }^{\prime}$ & 4.4078 & -0.0599 & 0.0404 & 0.0658 & -0. & & 0.0618 & 0.0807 & 0.059 & & 0.174 & 0.1431 \\
\hline $\mathrm{A}-\mathrm{H}_{3}{ }^{\prime}$ & 4.6788 & -0.1275 & -0.0229 & -0.0794 & -0. & & 0.0436 & -0.0377 & 0.006 & & 0.0105 & 0.0593 \\
\hline $\mathrm{G}-\mathrm{H}_{3}{ }^{\prime}$ & 4.5076 & -0.1292 & -0.029 & -0.0537 & -0 & & 0.0644 & 0.0445 & 0.0459 & & 0.0333 & 0.0674 \\
\hline $\mathrm{C}-\mathrm{H}_{3}{ }^{\prime}$ & 4.4794 & -0.1336 & -0.0189 & -0.0431 & & & 0.0364 & 0.0498 & -0.0147 & & 0.0454 & -0.043 \\
\hline $\mathrm{U}-\mathrm{H}_{3}{ }^{\prime}$ & 4.495 & -0.119 & -0.0065 & -0.0447 & & & 0.0506 & 0.1024 & 0.0229 & & 0.0657 & 0.0839 \\
\hline Atom & suc_ug & 5 ter & 3 ter & 3loop & 5loop & GU & corr & rms & nobs & xcorr & xrms & ntrim \\
\hline art 2 & & & & & & & & & & & & \\
\hline $\mathrm{A}-\mathrm{H}_{2}$ & 0.0804 & 0.1558 & 0 & 0.0274 & 0.0622 & 0 & 0.9868 & 0.0562 & 162 & 0.9845 & 0.0608 & 1 \\
\hline $\mathrm{A}-\mathrm{H}_{8}$ & -0.0261 & 0.3206 & 0 & -0.0175 & 0.08 & 0 & 0.9535 & 0.0575 & 157 & 0.9406 & 0.065 & 0 \\
\hline $\mathrm{G}-\mathrm{H}_{8}$ & -0.0671 & 0.3563 & -0.0607 & -0.0253 & 0.0332 & -0.0529 & 0.9655 & 0.0658 & 288 & 0.9612 & 0.0697 & 2 \\
\hline $\mathrm{C}-\mathrm{H}_{5}$ & -0.0958 & 0.1245 & -0.016 & -0.0205 & 0.01 & 0 & 0.9674 & 0.0478 & 256 & 0.9635 & 0.0505 & 5 \\
\hline $\mathrm{U}-\mathrm{H}_{5}$ & 0.047 & 0 & 0 & 0 & 0.0216 & 0.2747 & 0.9692 & 0.0537 & 178 & 0.9623 & 0.0594 & 0 \\
\hline $\mathrm{C}-\mathrm{H}_{6}$ & -0.1132 & 0.2326 & -0.0359 & -0.0428 & 0.0311 & 0 & 0.9332 & 0.0558 & 260 & 0.9249 & 0.0591 & 0 \\
\hline $\mathrm{U}-\mathrm{H}_{6}$ & -0.0457 & 0 & -0.0287 & -0.0341 & 0.0268 & -0.0412 & 0.9444 & 0.0446 & 172 & 0.9331 & 0.0489 & 4 \\
\hline $\mathrm{A}-\mathrm{H}_{1}{ }^{\prime}$ & -0.0353 & 0.0966 & 0 & -0.0173 & 0.0061 & 0 & 0.8476 & 0.0332 & 157 & 0.7905 & 0.0384 & 0 \\
\hline $\mathrm{G}-\mathrm{H}_{1}{ }^{\prime}$ & 0 & 0.1435 & -0.0376 & 0 & 0 & 0 & 0.9278 & 0.0415 & 284 & 0.9209 & 0.0434 & 3 \\
\hline $\mathrm{C}-\mathrm{H}_{1}{ }^{\prime}$ & -0.0224 & 0.1351 & 0.0114 & -0.0168 & 0.0121 & 0 & 0.8355 & 0.0427 & 253 & 0.7872 & 0.0482 & 5 \\
\hline $\mathrm{U}-\mathrm{H}_{1}{ }^{\prime}$ & 0.0328 & 0 & 0.0183 & 0.0145 & 0.0403 & -0.0316 & 0.7411 & 0.053 & 172 & 0.6451 & 0.0609 & 1 \\
\hline $\mathrm{A}-\mathrm{H}_{2}{ }^{\prime}$ & 0.1044 & 0.0702 & 0 & -0.0115 & 0.0291 & 0 & 0.7512 & 0.0618 & 143 & 0.6531 & 0.0714 & 0 \\
\hline $\mathrm{G}-\mathrm{H}_{2}{ }^{\prime}$ & 0.1022 & 0.074 & -0.1122 & -0.0326 & -0.0257 & 0.1211 & 0.8675 & 0.0516 & 246 & 0.8359 & 0.057 & 2 \\
\hline $\mathrm{C}-\mathrm{H}_{2}{ }^{\prime}$ & 0.1198 & 0.085 & -0.1316 & 0 & 0 & 0 & 0.9014 & 0.0589 & 217 & 0.8774 & 0.0654 & 4 \\
\hline $\mathrm{U}-\mathrm{H}_{2}{ }^{\prime}$ & 0.1691 & 0 & -0.229 & -0.0488 & -0.03 & -0.3095 & 0.92 & 0.0609 & 146 & 0.8999 & 0.0679 & 2 \\
\hline $\mathrm{A}-\mathrm{H}_{3}{ }^{\prime}$ & 0.0283 & 0.0235 & 0 & -0.0248 & 0.0202 & 0 & 0.5997 & 0.064 & 129 & 0.4933 & 0.0708 & 0 \\
\hline $\mathrm{G}-\mathrm{H}_{3}{ }^{\prime}$ & -0.0887 & 0.1061 & -0.0416 & -0.0146 & 0.0244 & -0.1527 & 0.7307 & 0.0807 & 226 & 0.6391 & 0.0914 & 3 \\
\hline $\mathrm{C}-\mathrm{H}_{3}{ }^{\prime}$ & -0.1182 & 0.1326 & -0.0178 & 0.0096 & -0.0224 & 0 & 0.7442 & 0.062 & 191 & 0.6942 & 0.0669 & 4 \\
\hline $\mathrm{U}-\mathrm{H}_{3}{ }^{\prime}$ & -0.0268 & 0 & -0.0432 & -0.0187 & 0.0159 & 0.0266 & 0.7047 & 0.0482 & 121 & 0.5928 & 0.0552 & 2 \\
\hline
\end{tabular}

Output from the Pace Regression analysis. Each row represents an individual atom type in the specified nucleotide (e.g., A- $\mathrm{H}_{2}$ is the $\mathrm{H}_{2}$ proton of Adenine). The column labeled const represents the chemical shift of that atom in the triplet $u X u$ when none of the additional attributes represented in subsequent columns are present. Contributions with values equal to 0 represent attributes that the Pace Regression algorithm found could not be supported by the data and were thereby automatically excluded from the regression analysis. The contribution from columns labeled pre_x and suc_x, where $\mathrm{x}$ is a,c,g, or gu are used where the preceding or succeeding nucleotide is not a $\mathrm{u}$. A GU attribute represents the case where the nucleotide is in a GU, rather than GC, base pair, and can apply to the $\mathrm{i}-1$ (pre_gu), $\mathrm{i}+1$ (suc_gu) or central (GU) triplet (with the same approach used for UG wobbles). The 5ter attribute indicates the triplet is at the $5^{\prime}$ end (so there is no $\mathrm{i}-2$ nucleotide), and 3 ter indicates the triplet is at the $3^{\prime}$ end (so there is no $\mathrm{i}+2$ nucleotide). The loop attributes indicate that the $\mathrm{i}-2$ (5loop) nucleotide or $\mathrm{i}+2$ (3loop) nucleotide is in a loop or mismatched base pair. The columns labeled corr and rms represent the correlation coefficient (corr) and the square root of the mean of squared deviations between predicted and experimental values (rms) for all the data in the fit. The columns labeled xcorr and xrms represent the same values, but calculated with 10-fold stratified cross-validation. The column labeled nobs represents the number of observations available and ntrim the number that were automatically eliminated as outliers 
Fig. 2 Plots of re-referenced ${ }^{1} \mathrm{H}$ NMR chemical shifts $(\delta)$ reported for the central adenosine residues within canonical triplets (as defined in text and Fig. 1 caption) versus mean shifts calculated for canonical triplets $\left(\langle\delta\rangle_{\text {can }}\right)$. a Data are shown for all adenosine protons grouped by atom type (symbols defined in a inset). b-d Expansions showing data grouped according to triplet sequence for the adenosine $\mathrm{H}_{2}(\mathbf{b}), \mathrm{H}_{8}$ (c) and ribose (d) protons (symbols defined in $\mathbf{b}$ inset) (a)

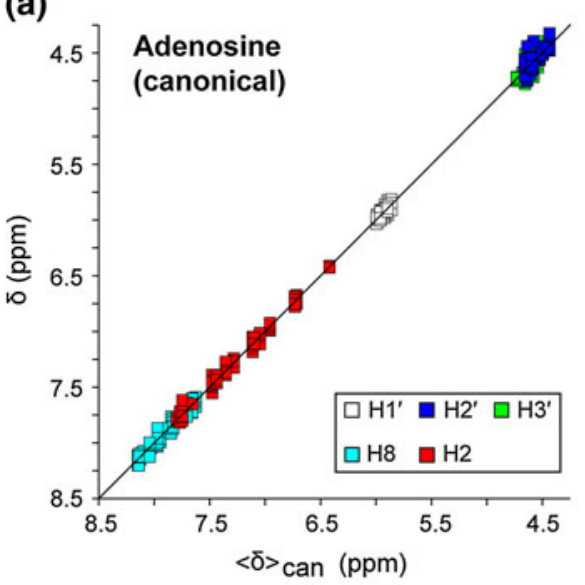

(c)

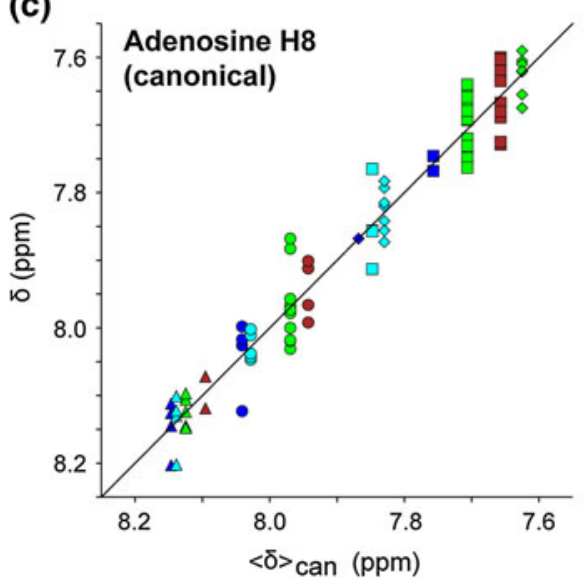

(b)

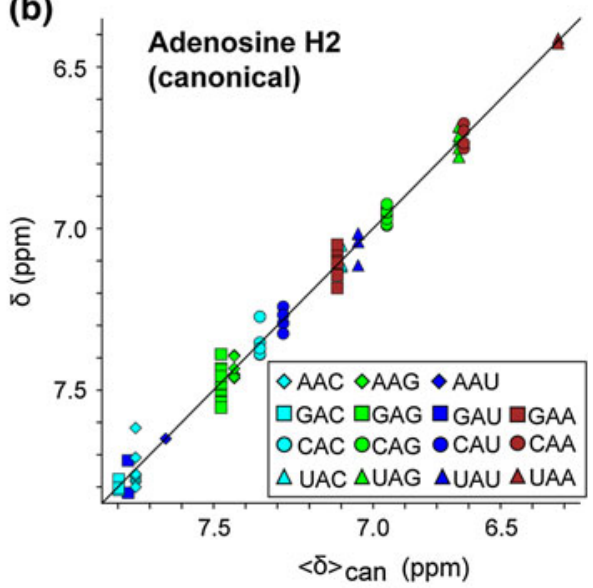

(d)

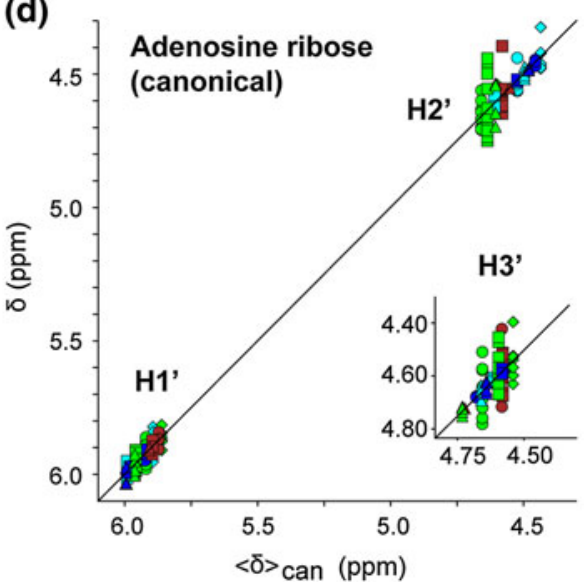

that, after automated re-referencing, deviated from expected values by more than 3 standard deviations. Seven of these assignments were associated with earlier publications from the M.F.S. laboratory, and inspection of the original NMR spectra revealed that these signals had been erroneously assigned (corrections to BMRB files 15113 and 17083 have now been made). We also discovered relatively large systematic chemical shift variations for one of our earlier depositions (BMRB ID 6094) that were associated with improper chemical shift referencing (the residual water signal at $35{ }^{\circ} \mathrm{C}$ was erroneously assigned a chemical shift of $4.792 \mathrm{ppm}$ ). We therefore updated the BMRB with the modified values, which were used in the present analysis. Based on examination of published NMR spectra, we were able to correct 19 additional assignments in the BMRB - in many cases, the signals had been properly assigned in the published spectra but improperly recorded in the BMRB files. In all cases, the re-assigned (or typocorrected) shifts were well within the 3-standard deviation cutoff. We were unable to determine the nature of the deviations observed for the remaining 38 outliers because relevant regions of the NMR spectra were not provided in the original publications, and these 38 assignments were not used in subsequent analyses. The majority of these outliers were associated with ribose protons, of which 17 were for highly overlapping $\mathrm{H}_{2}{ }^{\prime}$ and $\mathrm{H}_{3}{ }^{\prime}$ proton signals. Thus, of the 3,796 available chemical shifts, 3,758 were retained for analysis and $38(1 \%$; mostly ribose assignments) were excluded.

Chemical shifts that were either re-assigned or excluded are summarized in Supplementary Table S2, and referencing corrections employed for all of the utilized depositions are summarized in Supplementary Table S3. The final dataset included values for the central base pairs of all of the $4^{3}$ possible combinations of WC-BP triplets, with as few as one, and as many as 23 , assignments for each of the possible combinations. A total of 137 additional triplets that contain G:U base pairs were also included in the analysis. As shown in Fig. 1b, the retained and re-referenced BMRB shifts $(\delta)$ were in good agreement with predicted shifts $\left(\delta_{\text {pred }}\right)(\mathrm{rms}$ deviation for the entire dataset $=0.056$ ). Good agreement was also obtained when training was performed using a twofold cross-validation analysis, in which half of the data were used for training and half for validation $(\mathrm{rms}=0.069 \mathrm{ppm})$, and when training was performed with $60 \%$ of randomlyordered BMRB entries and validation assessed with the remaining $40 \%$ of the data $(\mathrm{rms}=0.063$, averaged over all atom types). 
Fig. 3 Plots of re-referenced ${ }^{1} \mathrm{H}$ NMR chemical shifts $(\delta)$ reported for the central guanosine (a), cytosine (b) and uracil (c) residues within canonical triplets (as defined in text and Fig. 1) versus mean shifts calculated for canonical triplets $\left(\langle\delta\rangle_{\text {can }}\right)$. Data are grouped by atom type as defined in panel insets (a)

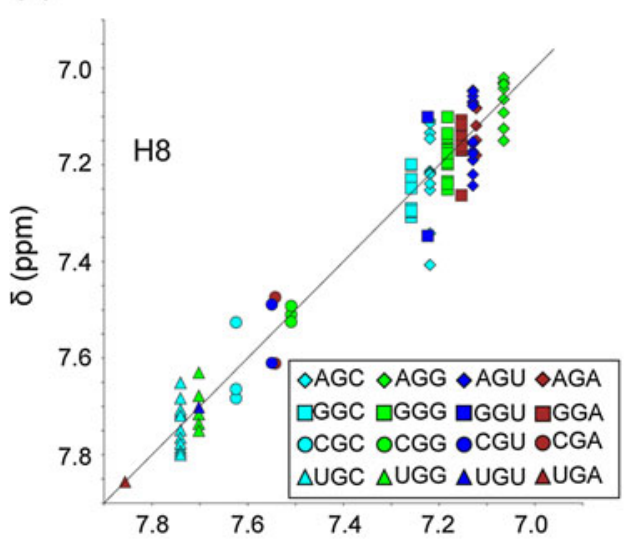

Guanosine (canonical)

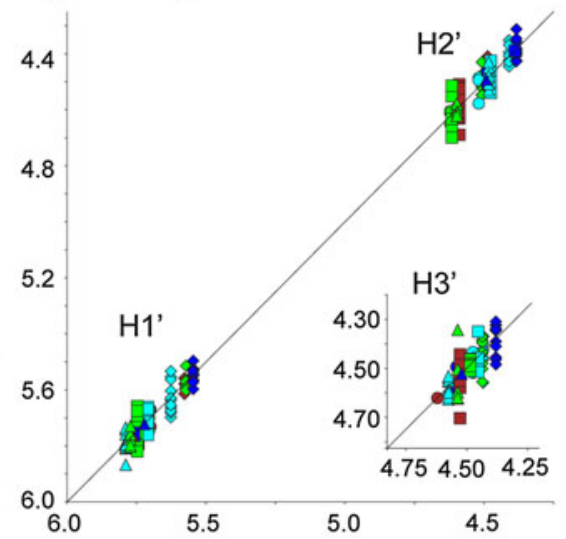

(b)

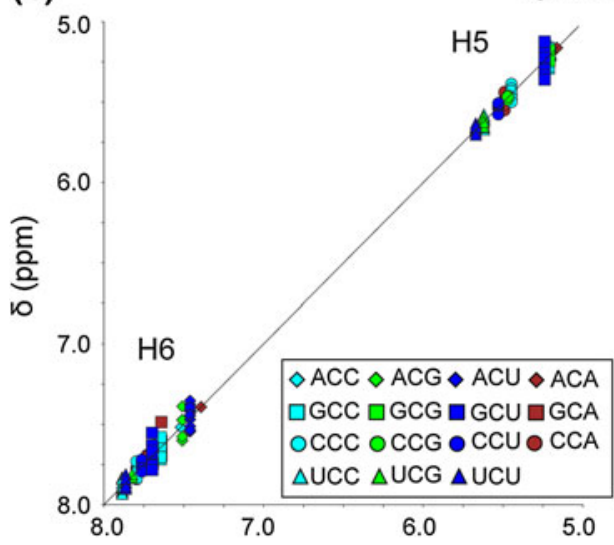

Cytosine (canonical)

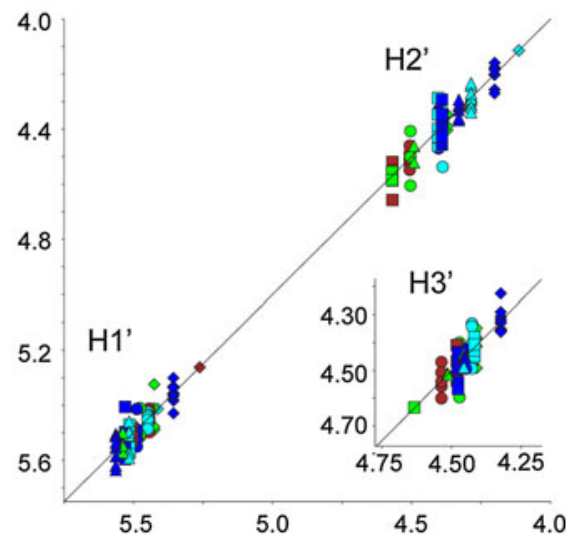

(c)

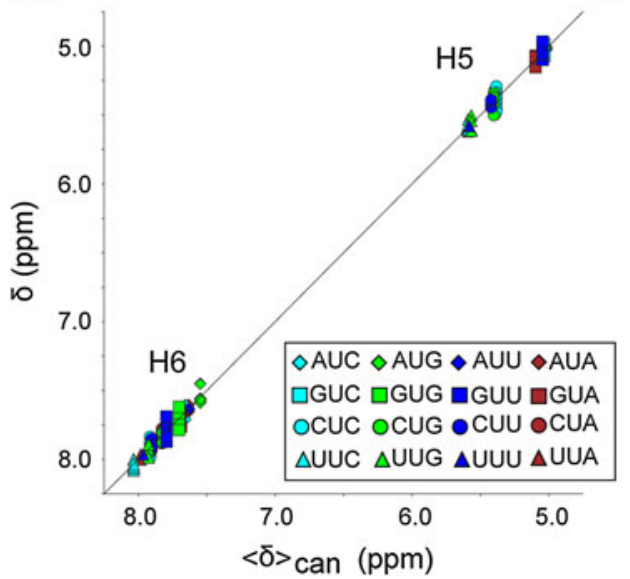

Uracil (canonical)

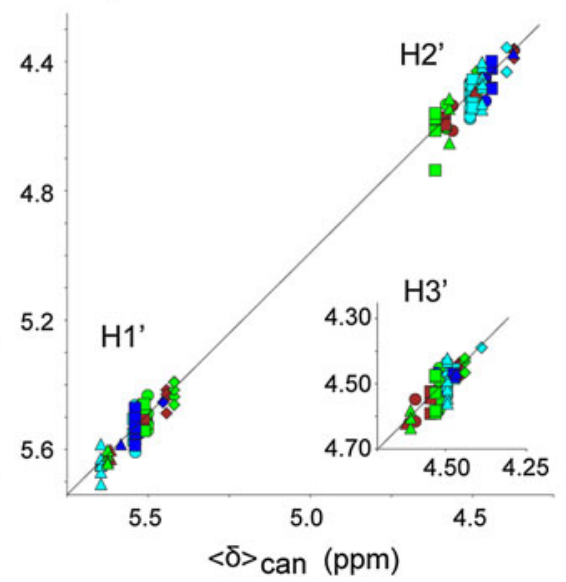

Chemical shift trends for canonical triplets

The re-referenced NMR chemical shifts ( $\delta$ ) were generally in good agreement with the mean shifts calculated for each unique sequence/atom type $(\langle\delta\rangle)$. For example, excellent correlations were observed in a plot of $\delta$ versus $\langle\delta\rangle$ for the central residues of "canonical triplets," defined here as a triplet that contains only GC and/or AU base pairs and are both preceded and followed by canonical GC or AU base pairs $($ rms deviation $=0.043$ ), Fig. 1c. The database utilized does not contain chemical shift values for aAa and $\mathrm{uCa}$ canonical triplets, nor for the $\mathrm{H}_{2}{ }^{\prime}$ and/or $\mathrm{H}_{3}{ }^{\prime}$ protons of the following canonical triplets: $\mathrm{aAu}\left(\mathrm{H}_{2}{ }^{\prime}, \mathrm{H}_{3}{ }^{\prime}\right), \mathrm{uGa}\left(\mathrm{H}_{2}{ }^{\prime}\right.$, $\mathrm{H}_{3}{ }^{\prime}$ ), aUu $\left(\mathrm{H}_{2}{ }^{\prime}, \mathrm{H}_{3}{ }^{\prime}\right), \mathrm{gGu}\left(\mathrm{H}_{3}{ }^{\prime}\right)$, aCc $\left(\mathrm{H}_{3}{ }^{\prime}\right)$. (Note that data were available for non-canonical forms of these triplets and were included in the analysis). There were no significant differences in correlation coefficients obtained upon fitting $\delta$ versus $\langle\delta\rangle$ for the $\mathrm{A}, \mathrm{G}, \mathrm{C}$ and $\mathrm{U}$ nucleotides, but as 
observed in plots of $\delta$ versus $\delta_{\text {pred, }}$ greater scatter was generally observed for the $\mathrm{H}_{2}{ }^{\prime}$ and $\mathrm{H}_{3}{ }^{\prime}$ protons, Fig. $2 \mathrm{a}$.

${ }^{1} \mathrm{H}$ NMR chemical shift trends were readily observed in plots that compare $\delta$ with the mean shift calculated for canonical triplets $\left(\langle\delta\rangle_{\text {can }}\right)$, and with the coefficients obtained with the Pace Regression analysis. Plots of $\delta$ versus $\langle\delta\rangle_{\text {can }}$ for the $n-A-n$ canonical triplets are shown in Fig. 2, and data for the n-G-n, n-C-n and n-U-n canonical triplets are plotted in Fig. 3. The contributions of the attributes calculated by Pace Regression are plotted in Fig. 4. The observed trends are consistent with several generalized correlations identified by Wijmenga and coworkers (Cromsigt et al. 2001). For example, $\delta$ values for purine- $\mathrm{H}_{8}$ protons in canonical triplets are highly sensitive to the nature of the $5^{\prime}$-residue within the triplet, with $5^{\prime}$-purines associated with more upfield chemical shifts. We further observe that $5^{\prime}$-uridines induce a larger downfield $\mathrm{H}_{8}$ shift than $5^{\prime}$-cytidines (Figs. 2c, 3a), and that the $\mathrm{H}_{8}$ chemical shift is also sensitive to the nature of the $3^{\prime}$-residue, Figs. 2c and 3a. For example, the $\mathrm{A}-\mathrm{H}_{8}\langle\delta\rangle_{\text {can }}$ values observed for $\mathrm{n}-\mathrm{A}-\mathrm{a}$ canonical triplets are consistently downfield relative to those observed for n-A-g canonical triplets, Fig. 2c, and a similar trend is observed for n-G-a versus n-G-g triplets, Fig. 3a.

The adenosine- $\mathrm{H}_{2}$ proton is sensitive to the nature of both the $5^{\prime}$ - and $3^{\prime}$-nucleotides (Cromsigt et al. 2001) and exhibits a large chemical shift range of $\sim 6.4-8.0 \mathrm{ppm}$. Importantly, the simultaneous presence of a $5^{\prime}$-pyrimidine and $3^{\prime}$-purine is associated with a significant upfield $\mathrm{A}-\mathrm{H}_{2}$ NMR chemical shift, to a less crowded region of the RNA NMR spectrum (6.4-7.1 ppm, Fig. 2b) where they are potentially useful for structural characterization of large RNAs Lu et al. (2011). In contrast, significant downfield shifts are observed for the $\mathrm{H}_{2}$ protons of adenosines that are preceded by a purine and followed by a pyrimidine, Fig. 2b. The $\mathrm{H}_{5}$ protons of the $\mathrm{C}$ and $\mathrm{U}$ are sensitive to the nature of the preceding residue of the triplet but exhibit almost no detectable sensitivity to the nature of the following residue, Fig. $3 \mathrm{c}$, d. The pyrimidine $\mathrm{H}_{6}$ protons are also more sensitive to the nature of the $5^{\prime}$ residue, but exhibit some sensitivity to the $3^{\prime}$ residue as well (Fig. 3c, e). The ribose protons appear to be sensitive to the nature of both the $5^{\prime}$ and $3^{\prime}$ residues, although the limited chemical shift dispersion and uncertainties regarding some of $\mathrm{H}_{2}{ }^{\prime}$ and $\mathrm{H}_{3}{ }^{\prime}$ assignments make it more difficult to identify clear chemical shift trends.

Influence of $5^{\prime}$ - and $3^{\prime}$-terminal base pairs within the WC-BP triplet

The presence of $5^{\prime}$ - and/or $3^{\prime}$-terminating base pairs within the WC-BP triplet has a significant influence on the chemical shifts of the central residue. As shown in Fig. 5a, the aromatic, $\mathrm{H}_{1}{ }^{\prime}, \mathrm{H}_{2}{ }^{\prime}$ and $\mathrm{H}_{3}{ }^{\prime}$ protons of the central residue exhibit small but significant downfield shifts relative to $\langle\delta\rangle_{\text {can }}$ values when adjacent to a $5^{\prime}$-terminating base-paired residue (the single $\mathrm{H}_{3}{ }^{\prime}$ outlier is most likely due to a misassignment or typo). The most significant perturbations are observed for the aromatic protons, which exhibit deviations in the range of 0.15-0.45 ppm. In contrast, most signals for residues that reside next to a $3^{\prime}$-terminal $\mathrm{WC}$-BP exhibit smaller but nevertheless consistent upfield shifts relative to the $\langle\delta\rangle_{\text {can }}$ values, Fig. 5b. The most significant shifts are observed for $\mathrm{H}_{2}{ }^{\prime}$ protons which have a mean upfield shift of $0.2 \mathrm{ppm}$.

Influence of non-canonical elements adjacent to the WCBP triplets

Our analysis assessed the influence of non-canonical structural elements that reside immediately upstream (5loop) or downstream (3loop) of the WC-BP triplets. We defined these elements to include internally stacked residues that are not involved in Watson-Crick base pairing, looped or bulge residues believed to be flexible or structured (e.g., K-turns), and residues involved in base-triples or long-distance RNA-RNA interactions. As shown in Fig. 5d, the presence of non-canonical RNA structures at the $3^{\prime}$-end of the WC-BP triplet does not appear to significantly influence any of the proton shifts associated with
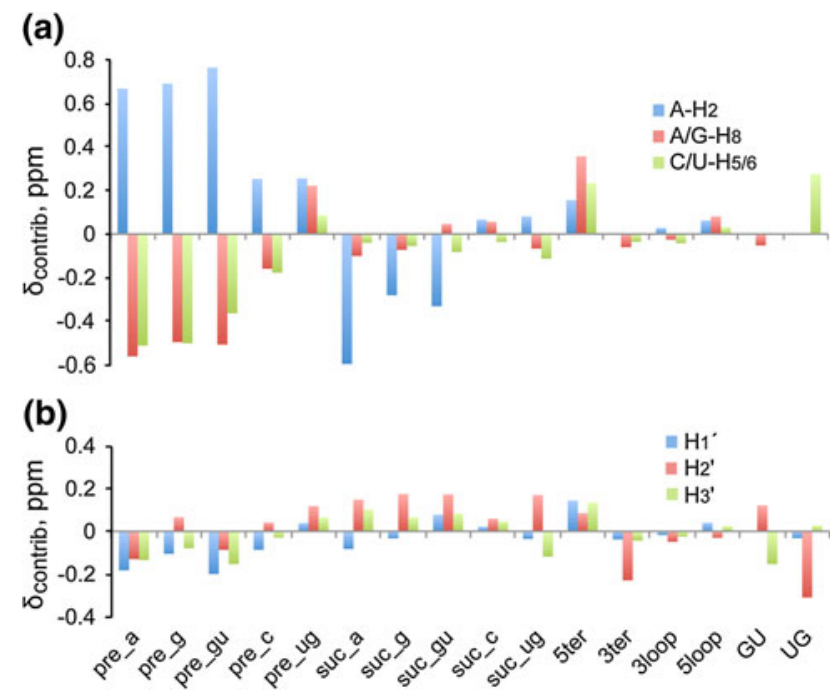

Fig. 4 Plot of the chemical shift contributions $\left(\delta_{\text {contrib }}\right)$ of each attribute relative to a canonical $\mathrm{uNu}$ triplet as obtained via Pace Regression for aromatic (a) and ribose (b) proton assignments (positive values denote downfield shifts). Data in these plots are derived from Table 1. For simplification, data for aromatic protons with similar trends in their response to the attributes were combined, and within each group of proton type, the largest absolute value is plotted. Because this procedure can mask the details of individual proton types one should use this plot for observing general trends and refer to the specific contributions in Table 1 
the central residue of the triplet. On the other hand, the presence of non-canonical structure on the $5^{\prime}$-side of the WC-BP triplet results in small but significant upfield shifts relative to $\langle\delta\rangle_{\text {can }}$ values for the aromatic and $\mathrm{H}_{1}{ }^{\prime}$ protons, Fig. 5c.

Influence of G:U base pairing within the triplet

Because GU base pairs are both prevalent and functionally important (Varani and McClain 2000), we also assessed the influence of this class of base pairing on ${ }^{1} \mathrm{H}$ NMR chemical shifts. Systematic variations are apparent for some protons of the central $U$ of triplets when they are base paired with G. Considering only canonical triplets in which the central U:A base pair is substituted by $\mathrm{U}: \mathrm{G}$, the $\mathrm{H}_{5}$ protons exhibit a downfield shift and the $\mathrm{H}_{1}{ }^{\prime}$ and $\mathrm{H}_{2}{ }^{\prime}$ protons exhibit small upfield shifts, whereas the $\mathrm{H}_{6}$ and $\mathrm{H}_{3}{ }^{\prime}$ chemical shifts appear to be relatively unperturbed, Fig. 6a. If the central residue of the canonical triplet is a $\mathrm{G}$, base pairing with $\mathrm{U}$ results in a small downfield shift of the $\mathrm{H}_{2}{ }^{\prime} \mathrm{NMR}$ signal and upfield shift of $\mathrm{H}_{3}{ }^{\prime}$ (relative to base pairing with $\mathrm{C}$ ) but does not significantly affect the shifts of the other G protons, Fig. $6 \mathrm{~b}$.

The presence of GU (or UG) base pairs at the $\mathrm{n}_{(\mathrm{i}-1)}$ or $\mathrm{n}_{(\mathrm{i}+1)}$ positions can significantly influence the signals of the central residue, and data for otherwise canonical triplets are shown in Fig. 6c-f. For triplets in which the central residues is a pyrimidine, the $\mathrm{H}_{1}{ }^{\prime}$ and $\mathrm{H}_{3}{ }^{\prime}$ are relatively unaffected by the presence of a preceding GU wobble, Fig. 6c. However, the $\mathrm{H}_{6}, \mathrm{H}_{5}$ and $\mathrm{H}_{2}{ }^{\prime}$ protons are systematically perturbed, with the $\mathrm{u}(\mathrm{wob})-\mathrm{U} / \mathrm{C}-\mathrm{n} \quad \mathrm{H}_{6}$ signal shifted downfield, the $\mathrm{g}(\mathrm{wob})-\mathrm{U}-\mathrm{n} \mathrm{H}_{6}$ signal shifted upfield, and the $\mathrm{g}$ (wob)-C-n C- $\mathrm{H}_{6}$ signal shifted downfield relative to the average canonical shifts, Fig. 6c. Interestingly, the $\mathrm{u}$ (wob)-C/U-n $\mathrm{H}_{5}$ shifts are relatively unperturbed relative to canonical shifts, whereas $\mathrm{g}(\mathrm{wob})-\mathrm{C} / \mathrm{U}-\mathrm{n}_{5}$ shifts are generally shifted downfield relative to the signals observed for the canonical triplets, Fig. $6 \mathrm{c}$. Also, $\mathrm{H}_{2}{ }^{\prime}$ shifts of the central pyrimidine are shifted downfield when preceded by a UG wobble, but are shifted upfield when preceded by a GU wobble, Fig. 6c. When the central residue is a purine, the $\mathrm{H}_{1}{ }^{\prime}$ and $\mathrm{H}_{3}{ }^{\prime}$ proton shifts are relatively unaffected by a preceding wobble, but the $\mathrm{H}_{8}, \mathrm{H}_{2}$, and $\mathrm{H}_{2}{ }^{\prime}$ protons generally exhibit systematic downfield shifts, with the magnitude of the shift being somewhat greater for a preceding U(wob) compared to a preceding $\mathrm{G}(\mathrm{wob})$, Fig. 6d.

The presence of a subsequent GU wobble can also result in systematic chemical shift perturbations. For triplets in which the central residue is a pyrimidine followed by a
Fig. 5 Plots of $\delta$ versus $\langle\delta\rangle_{\text {can }}$ (defined in Figs. 1, 2 captions) for the central residues of WC-BP triplets that contain a $5^{\prime}$-terminal base pair (5ter), a $3^{\prime}$-terminal base pair (3ter), or are preceded and/or followed by non-canonical loops or bulges (5loop and 3loop, respectively). Symbols are defined in the panel insets
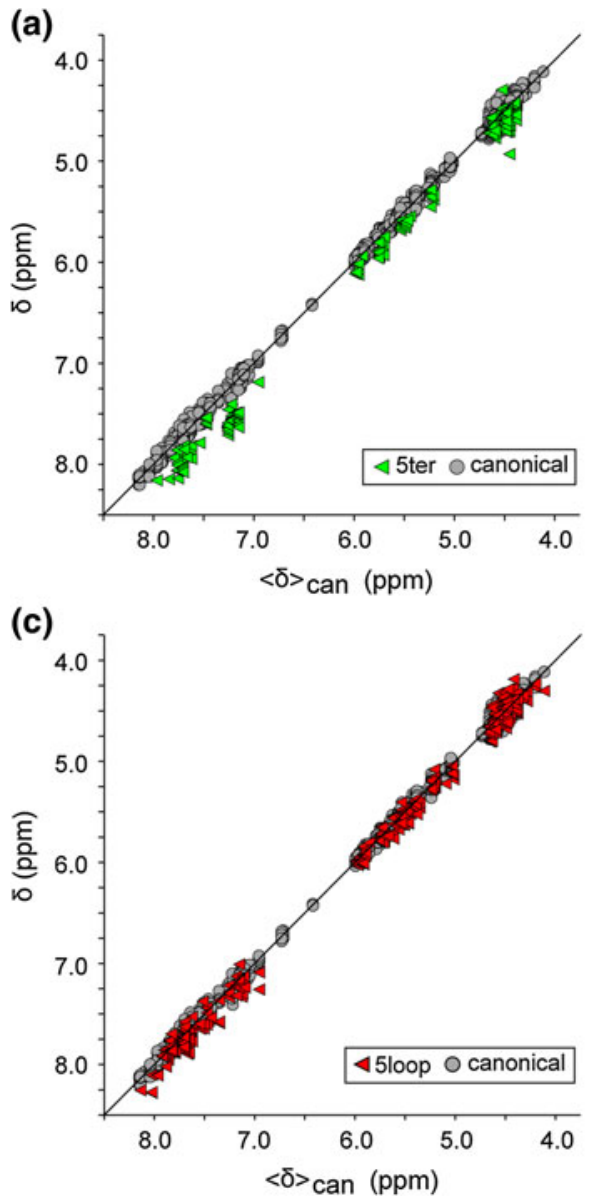

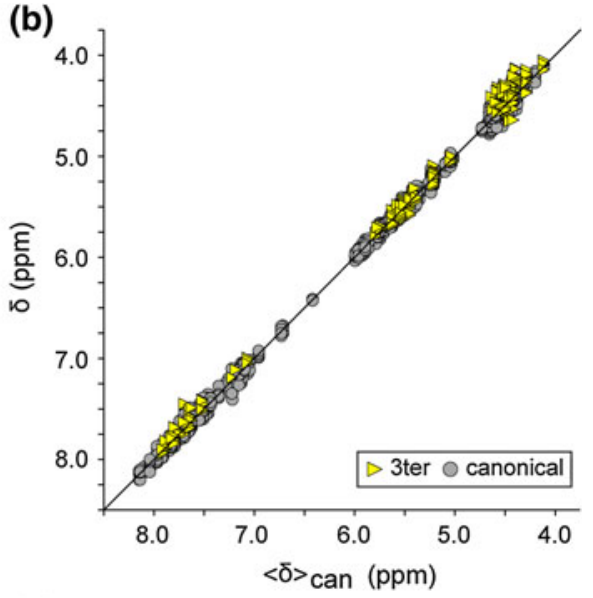

(d)

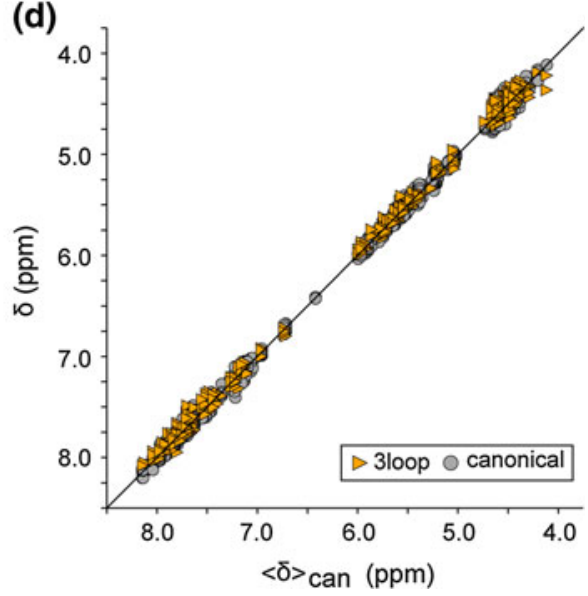


(a)

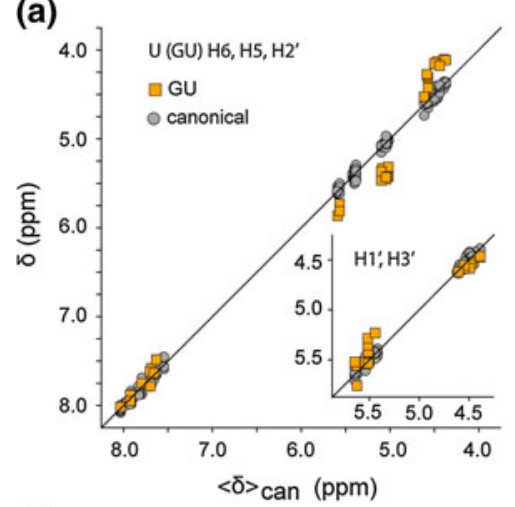

(d)

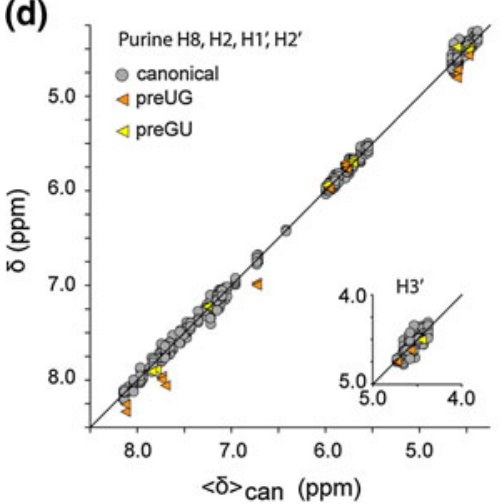

(b)

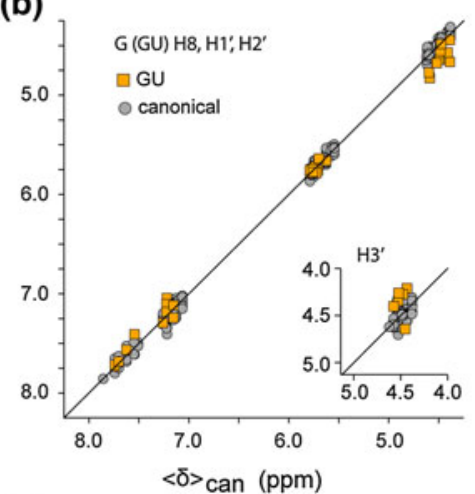

(e)

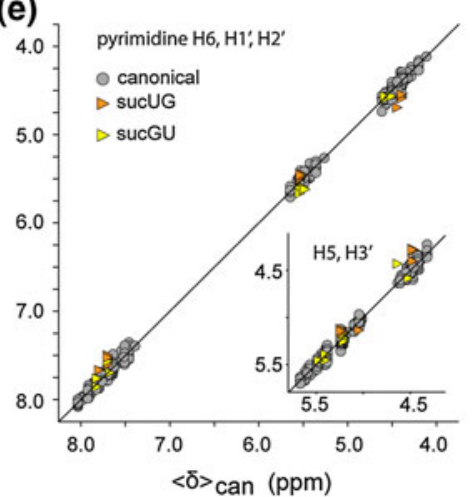

(c)

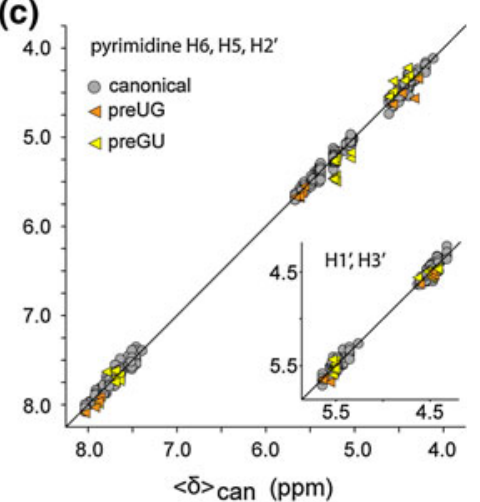

(f)

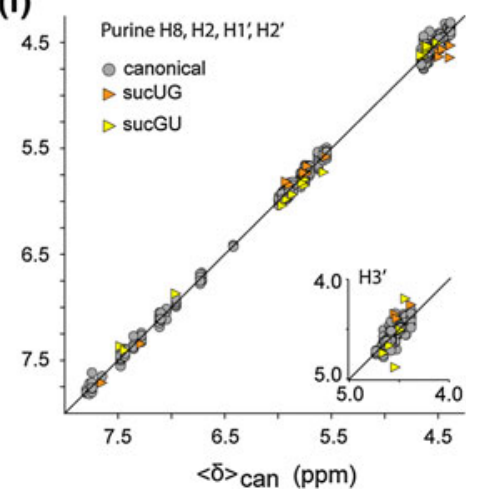

Fig. 6 Plots showing the sensitivity of the ${ }^{1} \mathrm{H}$ NMR chemical shifts to GU and UG wobble pairing within the canonical WC-BP triplet. a The central $U$ of an otherwise canonical triplet is paired with $G$. b The central $\mathrm{G}$ of an otherwise canonical triplet is paired with $\mathrm{U}$.

$\mathrm{U}$ (wob) mismatch, the $\mathrm{H}_{6}$ and $\mathrm{H}_{3}{ }^{\prime}$ signals exhibits small upfield shifts but the remaining signals do not appear to be significantly perturbed, Fig. 6e. In contrast, the presence of a subsequent $\mathrm{G}$ (wob) mismatch does not appear to lead to any detectable perturbations, Fig. 6e. For triplets in which the central residue is a purine, a subsequent $\mathrm{G}(\mathrm{wob})$ leads to a small systematic downfield shift of the $\mathrm{H}_{1}{ }^{\prime}$ proton but does not significantly perturb the other NMR signals, whereas a subsequent $\mathrm{U}(\mathrm{wob})$ pair results in small upfield shifts of the $\mathrm{H}_{6}$ and $\mathrm{H}_{5}$ signals and a small downfield shift of the $\mathrm{H}_{2}{ }^{\prime}$ signal, Fig. $6 \mathrm{f}$.

\section{Chemical shift predictions}

The Pace regression approach described above provided predicted chemical shift values for all possible combinations of WC-BP triplet parameters used in the present study, Table 1. ${ }^{1} \mathrm{H}$ NMR chemical shifts observed for the canonical triplets are in good agreement with the shifts predicted using the Pace regression approach described above $\left(\delta_{\text {pred }}\right)$, Fig. 7a $(\mathrm{rms}$ deviation $=0.050)$. Excellent agreement was also observed for triplets that contained only a single modifying element (e.g., only a 5ter but no other non-canonical elements), with the greatest deviations observed for a few of the c-f Influence of GU base pairs at the $\mathrm{n}_{(\mathrm{i}-1)}$ and $\mathrm{n}_{(\mathrm{i}+1)}$ position of the $\mathrm{n}_{(\mathrm{i}-1)}-\mathrm{N}_{\mathrm{i}}-\mathrm{n}_{(\mathrm{i}+1)}$ triplet on the NMR chemical shift of the central canonical base pair. Symbols are defined in the panel insets

$\mathrm{H}_{2}{ }^{\prime}$ and $\mathrm{H}_{3}{ }^{\prime}$ assignments, Fig. $7 \mathrm{~b}-\mathrm{h}$ (rms deviation in the range 0.057-0.057). Good fits were also observed for triplets that contained more than one modifying element (rms deviation for all canonical and non-canonical triplets $=0.056$ ), Fig. 7i. As observed in other fits, the largest deviations are observed for the $\mathrm{H}_{2}{ }^{\prime}$ and $\mathrm{H}_{3}{ }^{\prime}$ proton assignments.

The data in Table 1 can be used in computer programs such as NMRView (Johnson 2004; Johnson and Blevins 1994) or ad hoc calculations to predict chemical shifts. The constant term represents the value of the given atom in nucleotide $\mathrm{i}$, when the $\mathrm{i}-1$ and $\mathrm{i}+1$ nucleotides are both $\mathrm{U}$, and all nucleotides from $\mathrm{i}-2$ through $\mathrm{i}+2$ are present and in canonical Watson-Crick base pairs. For example, an A- $\mathrm{H}_{2}$ proton, in a canonical uAu triplet would be at 7.0299. Calculating the shift of the A- $\mathrm{H}_{2}$ proton in a different environment is done by adding to the constant term the contributions from any applicable columns in the $\mathrm{A}-\mathrm{H}_{2}$ row of Table 1. For example, the chemical shift of an $\mathrm{A}-\mathrm{H}_{2}$ proton in a gAc triplet, in which the $\mathrm{i}-2$ residue is in a loop, would be: $7.8469 \mathrm{ppm}(7.0299+0.6899+0.0658+0.0622)$. If the $\mathrm{i}-1 \mathrm{G}$ is in a GU (rather than GC) base pair, the A- $\mathrm{H}_{2}$ proton chemical shift would be: $7.9217 \mathrm{ppm}(7.0299+$ $0.7637+0.0658+0.0622)$. 
(a)

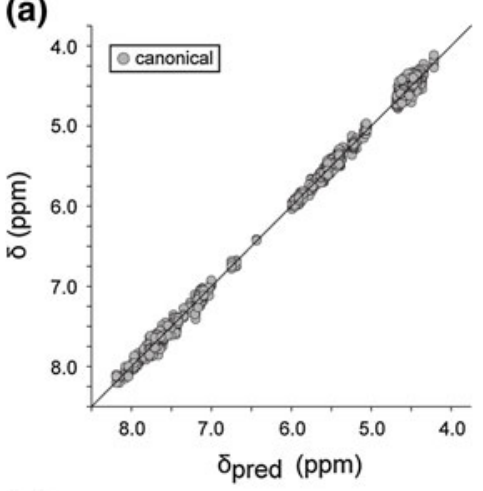

(d)

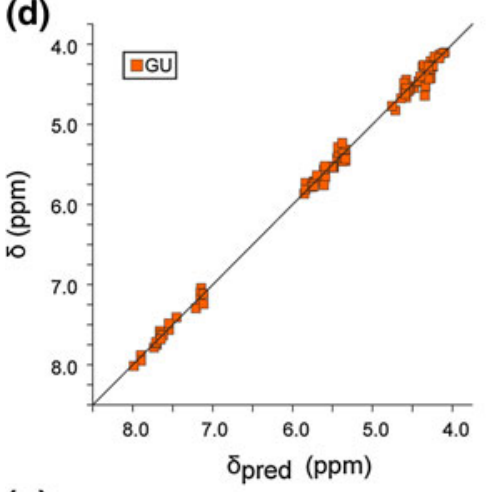

(g)

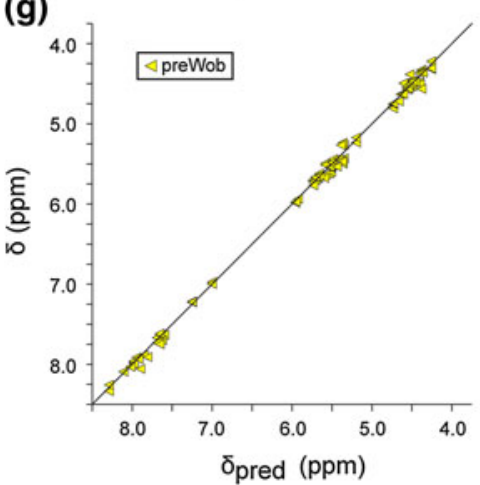

(b)

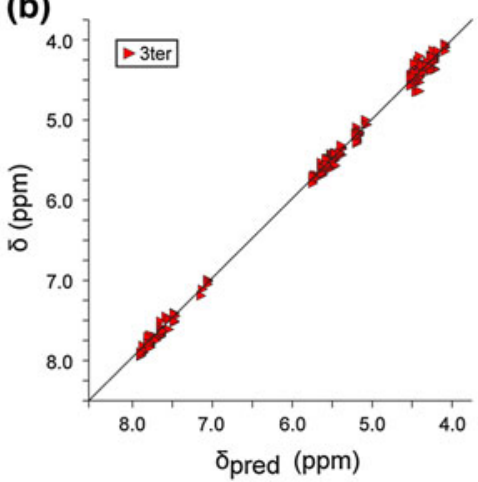

(e)

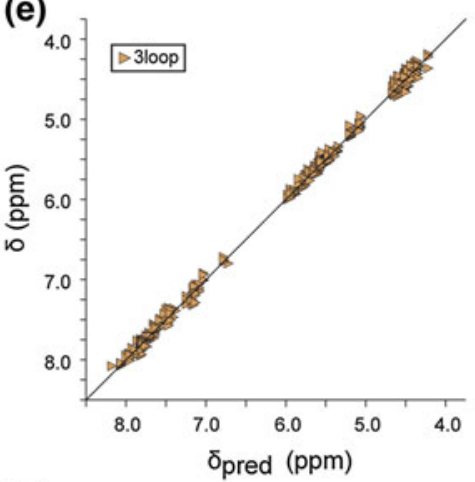

(h)

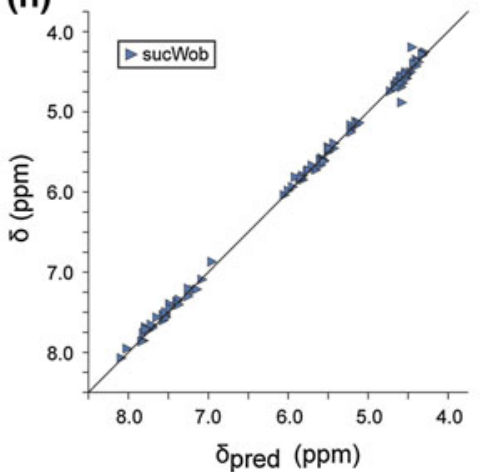

(c)

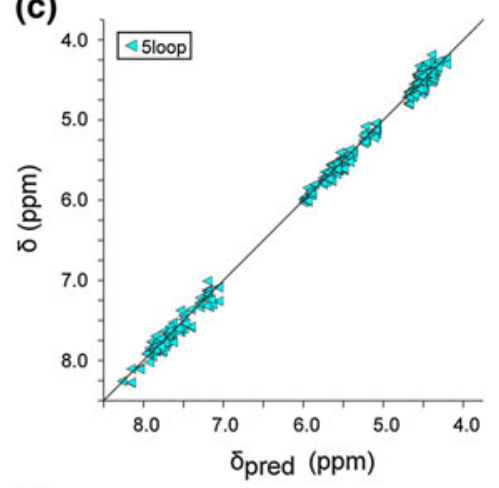

(f)

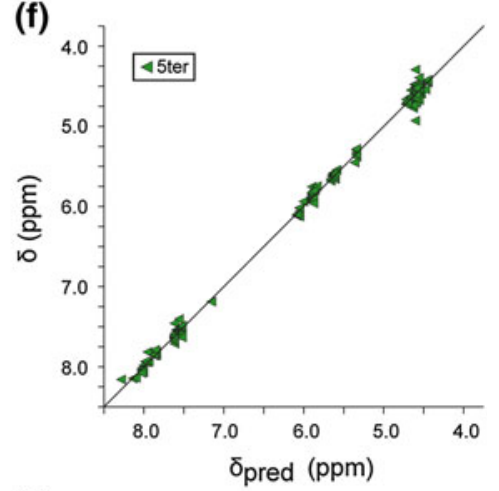

(i)

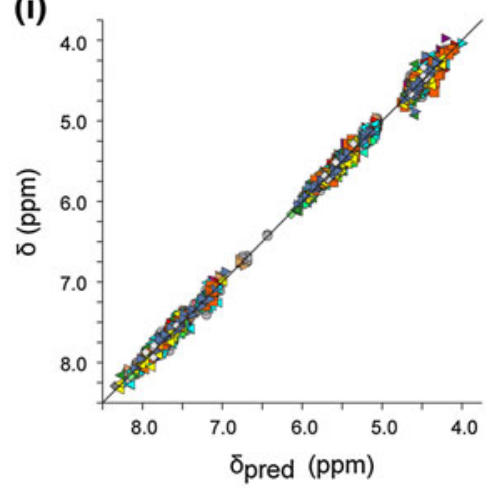

$\diamond$ sucWob/preWob \sucWob $\triangleleft$ preWob $\varangle$ GU/sucWob $\varangle$ GU/preWob $\square$ GU $\diamond 5$ ter/sucWob $\triangleleft 5$ ter/preWob

$\varangle$ GU/5ter $\varangle 5$ ter $\square$ 5loop/sucWob/preWob $\diamond 5$ loop/sucWob $\varangle$ 5loop/preWob $\square$ GU/5loop/sucWob $\square$ GU/5loop/preWob

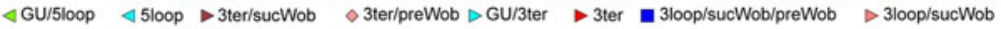

-3loop/preWob $\gg$ GU/3loop/sucWob $\gg$ GU/3loop/preWob $\gg$ GU/3loop $\gg 3 l o o p$ ocanonical

Fig. 7 Plots of $\delta$ versus predicted chemical shift $\left(\delta_{\text {pred }}\right)$, calculated by Pace regression as described in the text. $\mathbf{a}-\mathbf{h}$ Data for triplets that are fully canonical $(\mathbf{a})(\mathrm{rmsd}=0.050)$ or include a single non-canonical element, b 3'-terminal residue (3ter), rmsd $=0.054$; c loop, bulge or stacked non-BP residue immediately $5^{\prime}$ to the triplet, rmsd $=0.066$; d GU wobble at the center of an otherwise canonical triplet (GU), rmsd $=0.073$; e loop, bulge or stacked non-BP residue immediately

\section{Conclusions}

The present studies provide the first quantitative analysis of the RNA non-exchangeable ${ }^{1} \mathrm{H}$ NMR chemical shifts in the BMRB. Our studies identify sequence-dependent chemical shift correlations and establish the influence of terminating base pairs within the triplets and canonical and non- $3^{\prime}$ to the triplet (3ter), rmsd $=0.053$; f $5^{\prime}$-terminal residue within the triplet (5ter), rmsd $=0.054 ; \mathbf{g} 5^{\prime}$-residue of the triplet is involved in a GU wobble interaction (preWob), rmsd $=0.057 ; \mathbf{h} 3^{\prime}$-residue of the triplet is involved in a GU wobble interaction (sucWob), rmsd $=0.057 ; \mathbf{i}$ all data, including triplets with multiple noncanonical elements, rmsd $=0.056$

canonical structures adjacent to the BP triplets (i.e. bulges, loops, WC and non-WC BPs). Excellent correlations were observed despite the fact that the NMR data were obtained under different conditions of $\mathrm{pH}$, buffer, ionic strength, and temperature. A relatively small number of outliers that were not utilized in the analysis, mainly ribose $\mathrm{H}_{2}{ }^{\prime}$ and $\mathrm{H}_{3}{ }^{\prime}$ assignments, are likely due to assignment or typographical 
errors and should be re-examined. Assignments for some triplet combinations were either limited or lacking; for example, the database does not include assignments for two of the 64 possible "canonical triplets." Although shifts for these triplets could be predicted from assignments made for non-canonical triplets (e.g., WC-BP triplets adjacent to non-canonical structures or that contain terminal or $\mathrm{GC}$ base pairs), future studies of oligonucleotides with the missing sequences are clearly in order.

The statistics indicate that the protocol employed for chemical shift predictions, assigning attributes to different triplet environments and then conducting selection and linear model fitting with Pace Regression, performed very well for the data used in this study. However, as we move forward with this research and the number of attributes is expanded, alternative fitting methods such as Neural Networks and allowing attributes to contribute in non-linear modes may be required. The protocol used here can, of course, also be applied to nitrogen and carbon nuclei, and it will be interesting to determine if these nuclei exhibit similar environment- and structure-dependent sensitivities.

The ${ }^{1} \mathrm{H}$ NMR shifts observed for residues that participate directly in long-range RNA-RNA interactions or interactions with ligands or proteins, as identified in the associated publications and/or the structure coordinate (PDB) files, generally deviated from the A-form helical triplet shifts. For example, the $\mathrm{H}_{6}$ and $\mathrm{H}_{5}$ NMR chemical shifts observed for residue U5 of the ScYLV P-1-P2 frameshifting pseudoknot (7.93 and $5.25 \mathrm{ppm}$, respectively) (Cornish et al. 2005), deviate by 0.24 and $0.29 \mathrm{ppm}$ from the expected values (7.69 and 5.54 ppm, respectively) and are well outside the rms range calculated for canonical $\mathrm{gUg}$ triplets $(\mathrm{rms}=0.06$ and $0.03 \mathrm{ppm}$, respectively). Significant deviations were also observed for otherwise canonical A-form helical residues that interact with protein elements. In future studies of RNAs with unknown structures, the observation of outlier chemical shifts may serve as useful indicators of potential long-range RNA:RNA or RNA:protein interactions. In addition, the trends identified in the present studies should facilitate the refinement of algorithms used to calculate ${ }^{1} \mathrm{H}$ NMR chemical shifts on the basis of RNA structural coordinates alone (Cromsigt et al. 2001; Case 1995, 2002; Dejaegere et al. 1999; Case et al. 2005), thereby making the ${ }^{1} \mathrm{H}$ NMR chemical shift a more useful parameter for RNA structure refinement. Because the variations in chemical shifts observed for atoms of a given triplet are small, variations in the $3 \mathrm{D}$ structures of the triplets should also be small. This observation lends support for refinement approaches that utilize residual dipolar couplings and/or small angle X-ray scattering (SAXS) data to orient idealized A-form helices (Funari et al. 2000; Walsh et al. 2004; Zuo et al. 2008; Grishaev et al. 2008; Wang et al. 2009, 2010; Burke et al. 2012).
In the course of these studies, chemical shift trends were tentatively identified for a number of non-A-form helical structures that are well represented in the BMRB, particularly those of conserved tetraloops (e.g., GNRA). Future studies that include parameterizations for tetraloops, base triples, and other conserved and well-defined RNA substructures will likely lead to the identification of additional trends useful for ${ }^{1} \mathrm{H}$ NMR assignment and verification. In addition, it should now be possible to incorporate the approach into software programs to enable semi-automated assignment of RNA, including large RNAs with different combinations of ${ }^{2} \mathrm{H}$-labeled or segmentally-labeled nucleotides (underway).

Acknowledgments Support from the National Institute for General Medical Sciences (GM42561 to M.F.S. and GM103297 to B.J.) is gratefully acknowledged. S.B. was supported by grants from the National Institute of General Medical Sciences for enhancing minority access to research careers (MARC U*STAR 2T34 GM008663) and the Howard Hughes Medical Institute for enhancing undergraduate research training.

Open Access This article is distributed under the terms of the Creative Commons Attribution License which permits any use, distribution, and reproduction in any medium, provided the original author(s) and the source are credited.

\section{References}

Aeschbacher T, Schubert M, Allain FH (2012) A procedure to validate and correct the $13 \mathrm{C}$ chemical shift calibration of RNA datasets. J Biomol NMR 52:179-190

Allain FH-T, Varani G (1997) How accurately and precisely can RNA structure be determined by NMR? J Mol Biol 267:338-351

Bahrami A, Clos LJ 2nd, Markley JL, Butcher SE, Eghbalnia HR (2012) RNA-PAIRS: RNA probabilistic assignment of imino resonance shifts. J Biomol NMR 52:289-302

Bartel DP (2004) MicroRNAs: genomics, biogenesis, mechanism, and function. Cell 116:281-297

Batey RT, Inada M, Kujawinski E, Puglisi JD, Williamson JR (1992) Preparation of isotopically labeled ribonucleotides for multidimensional NMR spectroscopy of RNA. Nucleic Acids Res 20:4515-4523

Batey RT, Battiste JL, Williamson JR (1995) Preparation of isotopically enriched RNAs for heteronuclear NMR. Methods Enzymol 261:300-322

Bessonov S, Anokhina M, Will CL, Urlaub H, Luhrmann R (2008) Isolation of an active step I spliceosome and composition of its RNP core. Nature 452:846-850

Boisvert FM, van Koningsbruggen S, Navascues J, Lamond AI (2007) The multifunctional nucleolus. Nat Rev Mol Cell Biol 8:574-585

Brodersen P, Voinnet O (2006) The diversity of RNA silencing pathways in plants. Trends Genet 22:268-280

Burke JE, Sashital DG, Zuo X, Wang YX, Butcher SE (2012) Structure of the yeast U2/U6 snRNA complex. RNA 18:673-683

Case DA (1995) Calibration of ring-current effects in proteins and nucleic acids. J Biomol NMR 6:341-346 
Case DA (2002) AMBER 7 users manual. University of California San Francisco

Case DA, Cheatham TEI, Darden T, Gohlke H, Luo R, Merz KMJ, Onufriev A, Simmerling C, Wang B, Woods R (2005) The Amber biomolecular simulation programs. J Computat Chem 26:1668-1688

Cavalli A, Salvatella X, Dobson CM, Vendruscolo M (2007) Protein structure determination from NMR chemical shifts. Proc Natl Acad Sci USA 104:9615-9620

Cornish PV, Hennig M, Giedroc DP (2005) A loop 2 cytidine-stem 1 minor groove interaction as a positive determinant for pseudoknot-stimulated -1 ribosomal frameshifting. Proc Natl Acad Sci USA 102:12694-12699

Cromsigt JAMTC, Hilbers CW, Wijmenga SS (2001) Prediction of proton chemical shifts in RNA. Their use in structure refinement and validation. J Biomol NMR 21:11-29

Davis JH, Tonelli M, Scott LG, Jaeger L, Williamson JR, Butcher SE (2005) RNA helical packing in solution: NMR structure of a $30 \mathrm{kDa}$ GAAA tetraloop-receptor complex. J Mol Biol 351:371-382

Dejaegere A, Bryce RA, Case DA (1999) An empirical analysis of proton chemical shifts in nucleic acids, In: Facelli $\mathrm{J}$ et al (eds) ACS symposium series: modeling NMR chemical shifts. American Chemical Society, Washington, DC, pp 194-206

Doudna JA, Rath VL (2002) Structure and function of the eukaryotic ribosome: the next frontier. Cell 109:153-156

D'Souza V, Summers MF (2004) Structural basis for packaging the dimeric genome of Moloney Murine Leukaemia Virus. Nature 431:586-590

D'Souza V, Dey A, Habib D, Summers MF (2004) NMR structure of the 101 nucleotide core encapsidation signal of the Moloney Murine Leukemia Virus. J Mol Biol 337:427-442

Duss O, Lukavsky PJ, Allain FH (2012) Isotope labeling and segmental labeling of larger RNAs for NMR structural studies. Adv Exp Med Biol 992:121-144

Ebrahimi M, Rossi P, Rogers C, Harbison GS (2001) Dependence of 13C NMR chemical shifts on conformations of RNA nucleosides and nucleotides. J Magn Reson 150:1-9

Edwards TE, Klein DJ, Ferre-D'Amare AR (2007) Riboswitches: small-molecule recognition by gene regulatory RNAs. Curr Opin Struct Biol 17:273-279

Ehresmann C, Baudin F, Mougel M, Romby P, Ebel JP, Ehresmann B (1987) Probing the structure of RNAs in solution. Nucleic Acids Res 15:9109-9128

Fares C, Amata I, Carlomagno T (2007) 13C-detection in RNA bases: revealing structure-chemical shift relationships. J Am Chem Soc 129:15814-15823

Forconi M, Herschlag D (2009) Metal ion-based RNA cleavage as a structural probe. Methods Enzymol 468:91-106

Funari SS, Rapp G, Perbandt M, Dierks K, Vallazza M, Betzel C, Erdmann VA, Svergun DI (2000) Structure of free Thermus flavus $5 \mathrm{~S}$ rRNA at $1.3 \mathrm{~nm}$ resolution from synchrotron X-ray solution scattering. J Biol Chem 275:31283-31288

Grishaev A, Ying J, Canny MD, Pardi A, Bax A (2008) Solution structure of tRNAVal from refinement of homology model against residual dipolar coupling and SAXS data. J Biomol NMR 42:99-109

Grzesiek S, Bax A (1993) Amino acid type determination in the sequential assignment procedure of uniformly ${ }^{13} \mathrm{C} /{ }^{15} \mathrm{~N}$-enriched proteins. J Biomol NMR 3:185-204

Hassouna N, Michot B, Bachellerie JP (1984) The complete nucleotide sequence of mouse $28 \mathrm{~S}$ rRNA gene. Implications for the process of size increase of the large subunit rRNA in higher eukaryotes. Nucleic Acids Res 12:3563-3583

Heng X, Kharytonchyk S, Garcia EL, Lu K, Sachin Divakaruni S, LaCotti C, Edme K, Telesnitsky A, Summers MF (2012)
Identification of a minimal HIV-1 RNA packaging signal. J Mol Biol 417:224-239

Houck-Loomis B, Durney MA, Salguero C, Shankar N, Nagle JM, Goff SP, D'Souza VM (2011) An equilibrium-dependent retroviral mRNA switch regulates translational recoding. Nature 480:561-564

Johnson BA (2004) Using NMRView to visualize and analyze the NMR spectra of macromolecules. Methods Mol Biol 278:313-352

Johnson BA, Blevins RA (1994) NMRview: a computer program for the visualization and analysis of NMR data. J Biomol NMR 4:603-614

Kim VN (2005) Small RNAs: classification, biogenesis, and function. Mol Cells 19:1-15

Kim I, Watanabe S, Muto Y, Hosono K, Takai K, Takaku H, Kawai G, Watanabe K, Yokoyama S (1995) Selective deuteration of RNA for NMR signal assignment. Nucleic Acids Symp Ser 34:123-124

Kim I, Lukavsky PJ, Puglisi JD (2002) NMR study of 100 kDa HCV IRES RNA using segmental isotope labeling. J Am Chem Soc 124:9338-9339

Kladwang W, Vanlang CC, Cordero P, Das R (2011) Understanding the errors of SHAPE-directed RNA structure modeling. Biochemistry 50:8049-8056

Korostelev A, Noller HF (2007) The ribosome in focus: new structures bring new insights. Trends Biochem Sci 32:434-441

Lam SL, Chi LM (2010) Use of chemical shifts for structural studies of nucleic acids. Prog Nucl Magn Reson Spectrosc 56:289-310

Lu K, Miyazaki Y, Summers MF (2009) Isotope labeling strategies for NMR studies of RNA. J Biomol NMR 46:113-125

Lu K, Heng X, Garyu L, Monti S, Garcia E, Kharytonchyk S, Dorjsuren B, Kulandaivel G, Jones S, Hiremath A, Sachin Divakaruni S, LaCotti C, Barton S, Tummillo D, Hosic A, Edme K, Albrecht S, Telesnitsky A, Summers MF (2011a) NMR detection of structures in the HIV-1 5'-leader RNA that regulate genome packaging. Science 344:242-245

Lu K, Heng X, Summers MF (2011b) Structural determinants and mechanism of HIV-1 genome packaging. J Mol Biol 410:609-633

Lukavsky PJ, Puglisi JD (2005) Structure determination of large biological RNAs. Methods Enzymol 394:399-415

Lukavsky PJ, Kim I, Otto GA, Puglisi JD (2003) Structure of HCV IRES domain II determined by NMR. Nat Struct Biol 10:1033-1038

Michnicka MJ, Harper JW, King GC (1993) Selective isotopic enrichment of synthetic RNA: application to the HIV-1 TAR element. Biochemistry 32:395-400

Miyazaki Y, Irobalieva RN, Tolbert BS, Smalls-Manty A, Iyalla K, Loeliger K, D'Souza V, Khant H, Schmid MF, Garcia E, Telesnitsky A, Chiu W, Summers MF (2010) Structure of a conserved retroviral RNA packaging element by NMR spectroscopy and cryo-electron tomography. J Mol Biol 404:751-772

Nelissen FHT, van Gammeren AJ, Tessari M, Girard FC, Heus HA, Wijmenga SS (2008) Multiple segmental and selective isotope labeling of large RNA for NMR structural studies. Nucl Acids Res 36:e89

Nikonowicz EP, Pardi A (1992) Three-dimensional heteronuclear NMR studies of RNA. Nature 355:184-186

Nikonowicz EP, Sirr A, Legault P, Jucker FM, Baer LM, Pardi A (1992) Preparation of ${ }^{13} \mathrm{C}$ and ${ }^{15} \mathrm{~N}$ labelled RNAs for heteronuclear multi-dimensional NMR studies. Nucleic Acids Res 20:4507-4513

Ohlenschlager O, Haumann S, Ramachandran R, Gorlach M (2008) Conformational signatures of $13 \mathrm{C}$ chemical shifts in RNA ribose. J Biomol NMR 42:139-142 
Ousterhout JK, Jones K (2010) Tcl and the Tk Toolkit, 2nd edn. Addison-Wesley, Upper Saddle River, NJ

Peattie DA, Gilbert W (1980) Chemical probes for higher-order structure in RNA. Proc Natl Acad Sci USA 77:4679-4682

Peterson RD, Theimer CA, Wu H, Feigon J (2004) New applications of 2D filtered/edited NOESY for assignment and structure elucidation of RNA and RNA-protein complexes. J Biomol NMR 28:59-67

Ponting CP, Oliver PL, Reik W (2009) Evolution and functions of long noncoding RNAs. Cell 136:629-641

Pretsch E, Bühlmann P, Badertscher M (2009) Structure determination of organic compounds: tables of spectral data, 4th edn. Springer, Berlin

Shen Y, Lange O, Delaglio F, Rossi P, Aramini JM, Liu G, Eletsky A, Wu Y, Singarapu KK, Lemak A, Ignatchenko A, Arrowsmith CH, Szyperski T, Montelione GT, Baker D, Bax A (2008) Consistent blind protein structure generation from NMR chemical shift data. Proc Natl Acad Sci USA 105:4685-4690

Steitz TA (2008) A structural understanding of the dynamic ribosome machine. Nat Rev Mol Cell Biol 9:242-253

Stern S, Moazed D, Noller HF (1988) Structural analysis of RNA using chemical and enzymatic probing monitored by primer extension. Methods Enzymol 164:481-489

Tolbert BS, Miyazaki Y, Barton S, Kinde B, Starck P, Singh R, Bax A, Case DA, Summers MF (2010) Major groove width variations in RNA structures determined by NMR and impact of $13 \mathrm{C}$ residual chemical shift anisotropy and $1 \mathrm{H}-13 \mathrm{C}$ residual dipolar coupling on refinement. J Biomol NMR 47:205-219

Varani G, McClain WH (2000) The G x U wobble base pair. A fundamental building block of RNA structure crucial to RNA function in diverse biological systems. EMBO Rep 1:18-23

Wakeman CA, Winkler WC, Dann CE III (2007) Structural features of metabolite-sensing riboswitches. Trends Biochem Sci 32:415-424

Walsh JD, Cabello-Villegas J, Wang YX (2004) Periodicity in residual dipolar couplings and nucleic acid structures. J Am Chem Soc 126:1938-1939

Wang Y, Witten IH (2002) Modeling for optimal probability prediction. In: Proceedings of the 19th International Conference in Machine Learning, Sydney, Australia, pp 650-657
Wang J, Zuo X, Yu P, Xu H, Starich MR, Tiede DM, Shapiro BA, Schwieters CD, Wang YX (2009) A method for helical RNA global structure determination in solution using small-angle $\mathrm{x}$-ray scattering and NMR measurements. J Mol Biol 393:717-734

Wang YX, Zuo X, Wang J, Yu P, Butcher SE (2010) Rapid global structure determination of large RNA and RNA complexes using NMR and small-angle X-ray scattering. Methods 52:180-191

Weeks KM (2010) Advances in RNA structure analysis by chemical probing. Curr Opin Struct Biol 20:295-304

Wishart DS, Sykes BD (1994) The ${ }^{13} \mathrm{C}$ chemical-shift index: a simple method for the identification of protein secondary structure using ${ }^{13} \mathrm{C}$ chemical-shift data. J Biomol NMR 4:171-180

Wishart DS, Sykes BD, Richards FM (1991) Relationship between nuclear magnetic resonance chemical shift and protein secondary structure. J Mol Biol 222:311-333

Wishart DS, Sykes BD, Richards FM (1992) The chemical shift index: a fast and simple method for the assignment of protein secondary structure through NMR spectroscopy. Biochemistry 31:1647-1651

Wishart DS, Arndt D, Berjanskii M, Tang P, Zhou J, Lin G (2008) CS23D: a web server for rapid protein structure generation using NMR chemical shifts and sequence data. Nucleic Acids Res 36:W496-W502

Witten IH, Frank E, Hall MA (2011) Data mining: practical machine learning tools and techniques, 3rd edn. Morgan Kaupmann, USA

Wüthrich K (1986) NMR of proteins and nucleic acids. Wiley, New York

Xu J, Lapham J, Crothers DM (1996) Determining RNA solution structure by segmental isotopic labeling and NMR: application to Caenorhabditis elegans spliced leader RNA 1. Proc Natl Acad Sci USA 93:44-48

Zhou J, Bean RL, Vogt VM, Summers MF (2006) Solution structure of the Rous sarcoma virus nucleocapsid protein:uY RNA packaging signal complex. J Mol Biol 365:453-467

Zuo X, Wang J, Foster TR, Schwieters CD, Tiede DM, Butcher SE, Wang Y-X (2008) Global molecular structure and interfaces: refining an RNA:RNA complex structure using solution X-ray scattering data. J Am Chem Soc 130:3292-3293 